\title{
Correlation of Meaningfulness of Life to Psychological Time in Personality
}

\author{
Nailia R. Salikhova ${ }^{1}$ \\ ${ }^{1}$ Kazan Federal University, Kazan, Russia \\ Correspondence: Nailia R. Salikhova, Kazan Federal University, Kremlyovskaya st., 18, Kazan, 420008, Russia.
}

Received: June 6, 2013 Accepted: September 5, 2014 Online Published: September 29, 2014

doi:10.5539/ass.v10n19p291 URL: http://dx.doi.org/10.5539/ass.v10n19p291

\begin{abstract}
The article considers the issue of correlation between the meaning of life and psychological time of a personality, while the temporal distribution of the meaningful constituents in the human life is a very important aspect of the meaning of life. The specific issue concerning the ratio of the meaning of life's quantitative aspect manifested by means of its meaningfulness' level to some peculiar characteristics of the personality's psychological time was raised within the frames of the denoted problem. The aim of the present empirical research was to reveal the above mentioned correlation. The level of the meaningfulness of life was determined applying the Life-Purpose Orientations Questionnaire (LPO) that consists of five factors: goals in life, emotional intensity of life, self-actualization satisfaction, life locus of control, Ego locus of control. The parameters of the psychological time were estimated using the Estimation of Five-Year Intervals Method (EFI) that reveals the life way by means of its perceived efficiency's temporal dynamics. The current research surveyed the postgraduate students of the Kazan Federal University ( $\mathrm{n}=140$ ). The obtained findings reported that the level of the meaningfulness of life and such a parameter of the personality's psychological time, as a developmental age, demonstrate no interconnections: the surveyed, who are psychologically either younger, or older than their chronological age is, equally estimate their life as meaningful. At that, quantitative data on the meaningfulness of life are closely interconnected to other characteristics estimated by means of the EFI method to both the actualization and emotional intensity of life. The peculiarities of interconnections between the criteria of the meaningfulness of life and parameters of actualization and general emotional intensity of life for men and women were also detected. The men better evaluate the emotional intensity of both the past and future of their life at higher level of the meaningfulness of life. The women with the higher level of the meaningfulness of life better estimate its eventual intensity in the future, while they evaluate their past as poorer for events.
\end{abstract}

Keywords: meaning of life, meaningfulness of life, psychological time, self-actualization, emotional intensity of life

\section{Introduction}

The concept of meaning of life appeared in the psychology owing to V. Frankl (Frankl, 1963). The meaning of life is based on the structural hierarchy of major and minor meanings (Chudnovsky, 1999). The temporal distribution of the constituting meanings in the human life is one among the aspects of the above mentioned hierarchy.

At the moment, the various positions are expressed concerning the issue of correlation between the meaning and time in the psychology. B.S. Alishev (Alishev, 2010) denotes the difference between the concepts of "meaning" and "motive" through the direction of the time vector: the meaning is connected to the present and the past, while the motive - to the future. The more popular point of view relegates the notion of meaning, and especially meaning of life to the future. After D.A. Leontiev's conception, the meaning could be located both in the past, and present, and also future (Leontiev, 1999). The interrelation of the meaning of life's temporal properties with the personality's developmental crisis has been also fixed (Karpinsky, 2011).

The current research is dedicated to the peculiar issue within the frames of the denoted problem: the issue of correlation between the quantitative aspect of the meaning of life expressed through the degree of it meaningfulness, together with the parameters of the personality's psychological time (Kronik, 1987; Golovakha \& Kronik, 2008). 
As regard to the content, the meaning of life of each separate human-being is unique. As used herein, the issue of possible quantitative measuring of the meaning of life never comes up, however, the qualitative particularity of the meaning of life's content (Dezutter et al., 2014), its correlation to the psychological health and well-being (Brassai et al., 2011; Debats, 1996), to the mental states (Prokhorov, 2009), cross-cultural differentials in the meaning of life and axiological structures of personality (Salikhova, 2013) have already been all-sided explored.

Contrary to the meaning of life's content, the meaningfulness of life can be quantitatively estimated. For that very purpose, the Life-Purpose Orientations Questionnaire (LPO) is widely used. As following by this technique, the meaningfulness of life consists of five factors: goals in life, emotional intensity of life, self-actualization satisfaction, life locus of control, Ego locus of control (Leontiev, 1992). Three of these five factors correlate to the certain temporal location of meaning. The psychological future exists as the goals, while the present is represented with the experience of the emotional intensity of life, and finally, the past appears as the life's fruits satisfaction. As it seen, the LPO questionnaire evaluates the general meaningfulness of life mainly in the light of the personality's psychological time and arrives at a picture of the temporal distribution of meanings.

The estimation of the perceived temporal life transspective is also possible applying the other techniques. The Estimation of Five-Year Intervals Method (EFI) reveals the life way picture through its perceived efficiency's temporal dynamics in the self-awareness of the personality. The EFI procedure offers to evaluate all five-year intervals of the individual's own life since birth to the estimated moment of life end as for the degree of eventual intensity. In consequence, the characteristics reflecting the human's ideas concerning the correlation between the past, present and future in his own life are determined: i.e., life actualization, psychological age, adulthood index.

The LPO method is a verbal test including the series of paired opposing assertions. The interviewee evaluates particular sides of his own life in relation to specific verbal statements and so, expresses a certain compliance rate with one in each pair. The EFI technique actualizes the non-verbal mechanisms of human's realization of his own life. This method initiates the activity of both the memory and imagination directed to forming the ideas concerning the events in the past, present and future, which exist as emotionally-colored images.

Both the methods reflect to some degree the temporal life transspective of the human-being in whole and possess some similar parameters - just as in titles, so in essence - for example, life actualization evaluation, emotional intensity of life. That is why, the issue on the coincidence of the results obtained from their application, and the rate of coincidence or divergence in content of the measured parameters became appropriate. The aim of the current empirical exploration was to solve the above mentioned question.

\section{Methods}

The following methods were applied for obtaining the empirical evidences.

1) Life-Purpose Orientations Questionnaire (LPO) including the following parameters: goals in life (Goals), emotional intensity of life (Process), self-actualization satisfaction (Result), life locus of control (LC-Life), Ego locus of control (LC-Ego), general meaningfulness of life (ML).

2) The Estimation of Five-Year Intervals Method (EFI) that allows to estimate the following parameters: a) general emotional intensity of life (GEI), b) life actualization (A) up to the current moment as a ratio of the overall estimate of the previous stage of life to GEI, c) psychological age PA=(A*ELS)/100\%, where ELS expected lifespan, d) adulthood index $\mathrm{AI}=(\mathrm{PA} / \mathrm{CA}) * 100 \%$, where $\mathrm{CA}$ - chronological age.

The data were processed applying the descriptive statistics procedures, independent two-sample Student t-test, correlation analysis based on the Pearson's formula.

The current research has surveyed 140 postgraduate students of the Kazan Federal University ( 91 men and 49 women among them) at the age of 22 to 27 years studying natural sciences and mathematics.

\section{Results}

Two pairs of contrasting groups were separated from the aggregated sample after data retrieval using the above mentioned methods.

By measure of the meaningfulness of life, two groups: ML-H - high values of the meaningfulness of life (44 persons, including 28 men and 16 women, that is 31 per cent of total sample) and ML-L - low values of the meaningfulness of life (45 persons, including 31 men and 14 women, that is 32 per cent of total sample) were distinguished, see Table 1 .

By measure of the psychological age, two groups: Older - the psychological age is higher than the chronological one (40 persons, including 25 men and 15 women, that is 29 per cent of total sample) and Younger - the 
psychological age is lower than the chronological one (43 persons, including 31 men and 12 women, that is 30 per cent of total sample) were distinguished, see Table 2 .

The correlation analysis for all parameters against each other surveyed the data for the whole sample. Furthermore, the correlation analysis was also performed for the men and women's groups separately, while the tendencies of the meaningful control of life demonstrate the gender peculiarities (Salikhova, 2010).

Table 1. LPO Questionnaire Results in the Experimental Groups

\begin{tabular}{lllllll}
\hline \multirow{2}{*}{ Groups } & \multicolumn{2}{l}{ LPO Questionnaire's scales $\bar{a}(\sigma)$} & & \\
\cline { 2 - 7 } & Goals & Process & Result & LC-Ego & LC-Life & ML \\
\hline Ml-H (n=44) & $38.1(2.8)$ & $36.7(3.3)$ & $31.2(2.4)$ & $24.6(2.2)$ & $35.9(3.7)$ & $123.5(5.2)$ \\
ML-L (n=45) & $28.3(5.3)$ & $27.3(6.1)$ & $22.4(4.7)$ & $18.6(4.0)$ & $16.3(5.0)$ & $91.6(11.4)$ \\
T-actual & 10.8 & 9.0 & 10.9 & 8.8 & 9.2 & 17.0 \\
Differences' Significance & $\mathrm{p}<0.001$ & $\mathrm{p}<0.001$ & $\mathrm{p}<0.001$ & $\mathrm{p}<0.001$ & $\mathrm{p}<0.001$ & $\mathrm{p}<0.001$ \\
\hline
\end{tabular}

$\mathrm{t}$-test $=3.64(\mathrm{p}<0.001)$

Table 2. EFI Method Results in the Experimental Groups

\begin{tabular}{lllll}
\hline \multirow{2}{*}{ Groups } & \multicolumn{2}{l}{ EFI Method's parameters $\overline{\mathrm{a}}(\sigma)$} & \\
\cline { 2 - 5 } & PA & A & AI & GEI \\
\hline Older $(\mathrm{n}=40)$ & $29.9(6.2)$ & $34.2(5.7)$ & $133(5.3)$ & $106.9(3.5)$ \\
Younger $(\mathrm{n}=43)$ & $17.9(5.2)$ & $22.9(5.5)$ & $78.0(3.1)$ & $117.5(2.9)$ \\
T-actual & 13.8 & 7.5 & 15.4 & -1.5 \\
Differences' Significance & $\mathrm{p}<0.001$ & $\mathrm{p}<0.001$ & $\mathrm{p}<0.001$ & - \\
\hline
\end{tabular}

$\mathrm{t}$-test $=3.64(\mathrm{p}<0.001)$

Table 3. LPO Questionnaire Results Compared for Psychologically Younger and Older People

\begin{tabular}{lllllll}
\hline \multirow{2}{*}{ Groups } & \multicolumn{2}{l}{ LPO Questionnaire's scales ā $(\sigma)$} & & \\
\cline { 2 - 7 } & Goals & Process & Result & LC-Ego & Lc-Life & ML \\
\hline Older $(\mathrm{n}=40)$ & $33.7(5.2)$ & $31.8(4.7)$ & $27.0(6.3)$ & $22.1(3.6)$ & $31.6(7.2)$ & $107.2(14.5)$ \\
Younger $(\mathrm{n}=43)$ & $33.4(6.1)$ & $32.6(5.9)$ & $26.7(3.4)$ & $22.8(3.9)$ & $31.8(5.7)$ & $107.8(12.5)$ \\
T-actual & 0.24 & -0.64 & 0.32 & 0.36 & -0.22 & -0.18 \\
Differences' Significance & - & - & - & - & - & - \\
\hline t- & & & & &
\end{tabular}

$\mathrm{t}$-test $=2.01 \quad(\mathrm{p}<0.05)$

Table 4. EFI Method Results Compared For Groups of Individualswith High and Low Levels of Meaningfulness of Life

\begin{tabular}{lcccc}
\hline Groups & PA & A & AI & GEI \\
\hline ML-H $(\mathrm{n}=40)$ & $23.0(6.4)$ & $26.1(6.3)$ & $99.8(26.2)$ & $125.3(31.3)$ \\
ML-L $(\mathrm{n}=43)$ & $23.9(5.4)$ & $33.3(14.3)$ & $105.4(22.2)$ & $101.0(28.6)$ \\
T-actual & -0.73 & $\mathbf{- 3 . 0 9 * *}$ & -1.10 & $\mathbf{3 . 8 2} * * *$ \\
Differences' Significance & - & $\mathrm{p}<0.01$ & - & $\mathrm{p}<0.01$ \\
\hline
\end{tabular}

Table 5. Correlations Between the Results of LPO Questionnaire and EFI Method

\begin{tabular}{|c|c|c|c|c|c|c|c|c|c|}
\hline & \multirow{2}{*}{$\frac{\text { Aggregated Sample }}{\text { A }}$} & \multirow{2}{*}{$\frac{\text { Men }}{\text { GEI }}$} & \multicolumn{7}{|c|}{ Women } \\
\hline & & & $\mathrm{AI}$ & $\mathrm{A}$ & GEI & $\mathrm{AI}$ & $\mathrm{A}$ & GEI & $\mathrm{AI}$ \\
\hline$\overline{M L}$ & $-0.28 * * *$ & $0.35 * * *$ & -0.05 & $-0.22 *$ & $0.37 * * *$ & 0.00 & $-0.44 * *$ & 0.31* & -0.13 \\
\hline Goals & -0.15 & $0.25 * *$ & 0.05 & -0.10 & $0.28 * *$ & 0.11 & -0.26 & 0.18 & -0.05 \\
\hline Process & $-0.26^{* *}$ & $0.28 * * *$ & -0.11 & -0.16 & $0.32 * *$ & -0.05 & $-0.49 * * *$ & 0.18 & -0.23 \\
\hline Result & $-0.24 * *$ & $0.24 * *$ & -0.03 & -0.17 & $0.27 * *$ & 0.06 & $-0.41 * *$ & 0.17 & -0.19 \\
\hline LC-Ego & -0.16 & $0.32 * * *$ & 0.06 & -0.13 & $0.38 * * *$ & 0.08 & -0.23 & 0.16 & 0.02 \\
\hline LC-Life & $-0.19 *$ & 0.16 & -0.10 & -0.14 & 0.18 & -0.09 & $-0.31 \%$ & 0.12 & -0.09 \\
\hline
\end{tabular}

$*-\mathrm{p}<0.05 ; * *-\mathrm{p}<0.01 ; * * *-\mathrm{p}<0.001$ 


\section{Discussion}

The comparison of the Life-Purpose Orientations Questionnaire's results for the groups divided by the psychological age criterion has revealed no differences between these groups (Table 3). Both surveyed, who are psychologically younger, and those, who are psychologically older than their chronological age is, equally estimate their life as meaningful.

Somewhat different results were obtained in course of comparison of the groups divided by the level of the meaningfulness of life (Table 4). On the one hand, the comparison of the EFI Method's results detected the absence of any differences by the adulthood index. It means that both the surveyed with high and those with low levels of meaningfulness of life can feel themselves either psychologically younger or psychologically older than their chronological age is.

On the other hand, the sufficient differences between the groups were revealed as for self-actualization (A) and general emotional intensity of life (GEI). The individuals with higher level of the meaningfulness of life evaluate their life as richer for emotions as compared to those who demonstrate lower level of the meaningfulness of life. At that, the former distinguish themselves by lower self-actualization beyond all doubts, rather than the individuals with low level of the meaningfulness of life.

The obtained results are also evidenced by the correlations between the findings within the aggregated sample (Table 5). Nearly all figures of the LPO Questionnaire appeared to be directly connected to the emotional intensity of life. Those who evaluate the meaningfulness of life higher experience it as richer for emotions, as compared to those who estimate this parameter lower. This fact is coherent with the description of the LPO Questionnaire's scales (Leontiev, 1992), and also with the data obtained in course of other researches (Karpinsky, 2011; Salikhova, 2010).

The figures of the adulthood index obtained with the EFI Method appeared to be orthogonal to all findings of the Life Meaningfulness Test. Consequently, the psychological age, as self-perception either older, or younger than one's chronological age is, appeared to be never connected to either the life meaningful in whole, or to any of its constituents.

Significantly, almost all scales of the LPO Questionnaire correlate to the self-actualization index of the EFI Method: the higher the self-actualization is, the lower both the life present process' value and sense of life control are; also, the life is perceived less meaningful in whole. These findings allow to supplement and extend the interpretative resource of the self-actualization parameter within the EFI Method that has been previously offered by the authors of the technique (Kronik and Akhmerov, 2003).

Since the whole sample was divided into men and women's parts (Table 5), the interconnections between the LPO results and self-actualization (A), or emotional intensity of life (GEI) have divided between them. The reverse interconnection of the meaningfulness of life to the self-actualization is typical for the women only, while the interconnection of the meaningfulness of life to the emotional intensity of life - for the men. Consequently, at higher level of the meaningfulness of life the men evaluate higher all five-year intervals of their life (both past and future). They perceive the life richer for significant events. Whereas, the women with higher level of the meaningfulness of life evaluate the eventual intensity of their life higher for the future, while they perceive the past as trivial, not so rich for events just as the future. Respectively, they have worse findings for the self-actualization. These results coincide with the previously obtained data on the fact of the differences between the men and women as concerning the life meaningful regulation (Leontiev, 1999; Salikhova, 2010), on the one hand, and also cast light on the new aspects of the like differences, on the other.

\section{Conclusion}

The performed research has evidenced on the appropriateness of raising the issue on the connection between the level of the meaningfulness of life and psychological time of personality. At that, the complicated and contradictory pattern of interrelations between these life regulators was revealed. Some particular characteristics appeared to be interconnected, whereas the others were completely independent. The way of revealing the vision of the past, present and future, and also the gender self-identity has an important meaning.

The surveying of people with various education status, professional career, etc. is an upcoming trend aiming to verify the versatility of the revealed tendencies. Another necessary direction for further explorations is the extending and diversification of the methods and techniques applied for evaluation of the researched personal characteristics. 


\section{Findings}

1. The level of the meaningfulness of life and psychological age create orthogonal changes in the human's control of his life. Both who are psychologically younger and older than their chronological age is equally estimate their life as meaningful. At that, the individuals who demonstrate both high and low level of the meaningfulness of life can feel themselves either psychologically younger, or psychologically older than their chronological age is.

2. The values of the meaningfulness of life according to the LPO Questionnaire and the parameters of self-actualization and general emotional intensity of life by the EFI Method are tightly interconnected. That means they both reflect realities similar in their psychological essence.

3. The gender particularity of the interconnection between the values of the meaningfulness of life and the parameters of the self-actualization and emotional intensity of life. At higher level of the meaningfulness of life, the men better estimate the emotional intensity of their lives - both concerning the past and future. At the same time, the women with higher level of the meaningfulness of life better estimate the eventual intensity in the future, while the past seems to be poorer for events to them.

\section{References}

Alishev, B. S. (2010). Meaning and motive: Correlation between the concepts. Bulletin of the Kazan University. Series: Humanities, 152(5), 159-171.

Brassai, L., Piko, B. F., \& Steger, M. F. (2011). Meaning in life: Is it a protective factor for adolescents' psychological health? International Journal of Behavioral Medicine, 18(1), 44-51.

Chudnovsky, V. E. (1999). Revisiting the issue of the meaning of life's adequacy. World of Psychology, 2, 74-80.

Debats, D. L., (1996). Meaning in life: Clinical relevance and predictive power. British Journal of Clinical Psychology, 35(4), 503-516. http://dx.doi.org/10.1111/j.2044-8260.1996.tb01207.x

Dezutter, J., Waterman, A. S., Schwartz, K., Luyckx, S. J., Beyers, W., Meca, A., .. \& Caraway, S. J. (2014). Meaning in life in emerging adulthood: A person-oriented approach. Journal of Personality, 82(1), 57-68. http://dx.doi.org/10.1111/jopy.12033

Frankl, V. (1963). Man's search for meaning: An introduction to logotherapy (p. 120). Washington Square Press.

Golovakha, E. I., \& Kronik, A. A. (2008). Psychological time of a personality (2nd ed., updated, p. 267.). Moscow: Smysl.

Karpinsky, K. V. (2011). Temporal features of the meaning of life and life-purpose crisis in course of the development of personality. Proceedings of the Tula State University. Humanities, 3, 368-378.

Kronik, A. A. (1987). Psychological time. In the Concise Psychological Dictionary (pp. 240-241). New York, NY: International Publishers.

Kronik, A. A., \& Akhmerov, R. A. (2003). Causalmetry: Methods of self-cognition, psychodiagnosis and psychotherapy in the psychology of life journey (p. 267). Moscow: Smysl.

Leontiev, D. A. (1992). Life-Purpose Orientations Questionnaire (LPO) (p. 32). Moscow: Smysl.

Leontiev, D. A. (1999). Psychology of meaning: Essence, structure and dynamics of meaningful reality (p. 452). Moscow: Smysl.

Prokhorov, A. O., (2009). Notional regulation of mental states. PsikhologicheskiiZhurnal, 30(2), 5-17.

Salikhova, N. R. (2010). The realizability of personal values as a dynamic feature of the value-sense sphere of personality. Journal of Russian \& East European Psychology, 48(2), 79-94. http://dx.doi.org/10.2753/RPO 1061-0405480206

Salikhova, N. R. (2013). Characteristics of personal value-meaning systems: A comparative study of American and Russian university students. Procedia - Social and Behavioral Sciences, 86(Special issue dedicated to the V Congress of the Russian Psychological Society, Moscow), 349-354.

\section{Copyrights}

Copyright for this article is retained by the author(s), with first publication rights granted to the journal.

This is an open-access article distributed under the terms and conditions of the Creative Commons Attribution license (http://creativecommons.org/licenses/by/3.0/). 